\title{
Effect of polyethylene glycol and polyvinylpyrrolidone on in vitro gas production of raisin waste
}

A Taghizadeh ${ }^{1}$, M Besharati ${ }^{1,2}$

${ }^{1}$ University of Tabriz, Tabriz,East Azarbyjan, Islamic Republic of Iran

${ }^{2}$ Payame Noor University of Benis, Shabestar,East Azarbyjan, Islamic Republic of Iran

Email:ataghius@yahoo.com

Introduction In the Middle East, animals suffer from under feeding and malnutrition in winter due to the shortage of locally produced feeds which are not sufficient to cover the nutritional requirements of the animals (Besharati and Taghizadeh, 2009). The annual amount of agricultural by-products produced in Iran is large. The production of grape exceeds 2.87 million tonnes/year, with a high proportion of the yield being used for production of dried grape products. In this process, large amounts of raisin waste are produced. Raisin waste contains of pieces of raisin plus grape cluster stems. There is little information available on the nutritive value of raisin waste. However, inclusion of grape by-product in the diet reduced digestibilities of the diet (Baumgartel et al., 2007). Yinrong Lu and Yeap Foo (1999) reported that grape pomace tannins have adverse effects on nutrient utilisation, and are toxic at high intake levels (Reed, 1995) due to their ability to bind proteins, minerals and carbohydrates (McSweeney et al., 2001). Tannins are the most widely occurring antinutritional factor in non-conventional feeds. Polyethylene glycol (PEG) and polyvinylpyrrolidone (PVP) have a high affinity for tannins. Addition of PEG results in the formation of PEG-tannin complexes which inactivates tannins. The aim of this study was to determine the effect of PEG and PVP on in vitro gas production kinetics of raisin waste.

Material and methods The chemical composition of raisin waste was determined using the methods recommended by AOAC (1999). Neutral detergent fibre (NDF) and acid detergent fibre (ADF) concentrations were determined using the methods of Van Soest et al. (1991). Total phenolics (TP) were measured using the Folin Ciocalteau method (Makkar, 2000). Total tannin (TT) was determined after adding insoluble polyvinylpyrrolidone and reacting with Folin Ciocalteau reagent (Makkar, 2000). Tannic acid was used as the standard to express the amount of TP and TT. Ruminal fluid was collected from two fistulated sheep, about $2 \mathrm{~h}$ after their morning feed. Gas production was measured by the method of Fedorak and Hrudy (1983). Approximately $300 \mathrm{mg}$ of dried and ground (2 mm) raisin waste sample was weighed and placed into serum bottles in the presence $(300 \mathrm{mg})$ and in the absence of PEG and PVP. There were three replicates per treatments. The gas production was recorded after $2,4,6,8,12,16,24,36$, and $48 \mathrm{~h}$ of incubation. Total gas values were corrected for the blank incubation, and reported gas values are expressed in $\mathrm{ml} / \mathrm{g} \mathrm{DM}$. The data at the different times was analysed using completely randomised design by the GLM procedure of SAS Institute Inc (2002).

Results The chemical composition of raisin waste is presented in Table 1. Total gas production (ml/g DM) from raisin waste incubated with and without PEG or PVP at different incubation times are shown in Table 2. At the early incubation times (2 and $4 \mathrm{~h}$ ), the control treatment (no PEG and PVP) had the highest gas production volume among treatments, but up to $6 \mathrm{~h}$ of incubation time the gas production volumes for PEG and PVP treatments (Table 2) were increased $(\mathrm{p}<0.05)$.

Table 1 The chemical composition of raisin waste $(\mathrm{g} / \mathrm{kg} \mathrm{DM})$

\begin{tabular}{llllllll}
\hline \hline Feed & DM & CP & NDF & ADF & OM & Total phenols & Total tannins \\
\hline Raisin waste & 916 & 62.4 & 280 & 276 & 927.7 & 96.3 & 72.1 \\
\hline \hline
\end{tabular}

Table 2 Total gas production volume (ml/g DM) from raisin waste incubated with and without PEG or PVP.

\begin{tabular}{|c|c|c|c|c|c|c|c|c|c|}
\hline \multirow{2}{*}{ Treatments } & \multicolumn{9}{|c|}{ Incubation times $(\mathrm{h})$} \\
\hline & 2 & 4 & 6 & 8 & 12 & 16 & 24 & 36 & 48 \\
\hline Raisin waste & $33.1^{\mathrm{a}}$ & $73.8^{\mathrm{a}}$ & $101.0^{\mathrm{b}}$ & $118.7^{\mathrm{b}}$ & $141.8^{b}$ & $156.6^{\mathrm{b}}$ & $180.9^{b}$ & $203.2^{\mathrm{b}}$ & $208.7^{b}$ \\
\hline Raisin waste + PEG & $12.7^{\mathrm{b}}$ & $62.0 \mathrm{~b}$ & $109.6^{\mathrm{a}}$ & $134.3^{\mathrm{a}}$ & $158.4^{\mathrm{a}}$ & $180.3^{\mathrm{a}}$ & $204.4^{\mathrm{a}}$ & $229.4^{\mathrm{a}}$ & $247.1^{\mathrm{a}}$ \\
\hline Raisin waste + PVP & $9.8^{\mathrm{b}}$ & $54.4^{\mathrm{c}}$ & $104.6^{\mathrm{ab}}$ & $132.8^{\mathrm{a}}$ & $159.9^{\mathrm{a}}$ & $182.3^{\mathrm{a}}$ & $206.5^{\mathrm{a}}$ & $229.7^{\mathrm{a}}$ & $247.9^{\mathrm{a}}$ \\
\hline SEM & 1.41 & 1.49 & 1.85 & 2.51 & 3.51 & 3.74 & 3.87 & 3.64 & 3.54 \\
\hline
\end{tabular}

The means within a column without a common letter differ $(\mathrm{p}<0.05)$.

Conclusions PEG and PVP, which are non-nutritive synthetic polymers, have high affinities to tannins and makes tannins inert by forming tannin complexes. The increase in the gas production in the presence of PEG and PVP is possibly due to an increase in the available nutrients to rumen micro-organisms, especially the available nitrogen and PEG and PVP preventing the tannins from bonding with the protein, thus making the protein more digestible.

Acknowledgement This study was funded by University of Tabriz, Tabriz, Iran.

\section{References}

Baumgärtel, T., Kluth, H., Epperlein, K., Rodehutscord, M., 2007. Res. 67, 302-306.

Besharati, M. and A. Taghizadeh, 2009. Journal of Animal Feed Science and Technology. 152, 198-203.

Makkar, H.P.S. (Ed.).2000. Animal Production and Health Sub-programme, FAO/IAEA Working Document. IAEA, Vienna, Austria.

McSweeney, C.S., Palmer, B., McNeill, D.M. and Krause, D.O. 2001. Journal of Animal Feed Science and Technology. 91, 83-93.

Reed, J. D., 1995. J. Anim. Sci. 73, 1516-1528.

SAS Inc., 2002. SAS user's Guide: statistics. Statistical Analysis Systems Institute Inc. Cary NC.

Yinrong Lu, Yeap Foo, L., 1999. Food Chem. 65, 1-8. 